\title{
Paratesticular Paraganglioma
}

National Cancer Institute

\section{Source}

National Cancer Institute. Paratesticular Paraganglioma. NCI Thesaurus. Code C162490.

An extremely rare paragang lioma that arises from the paratesticular structures. 